\title{
The impact of the Disability Discrimination Act on historic buildings
}

Received: 23 rd September, 2005

\author{
Melanie Smith BSc, FRICS, CIAT, NRAC Consultant \\ is a senior lecturer in the School of the Built Environment at Leeds Metropolitan University. \\ She is a Chartered Building Surveyor and Fellow of the Royal Institution of Chartered Surveyors. \\ She sits on the RICS DDA Working Party and is a consultant member of the National Register of \\ Access Consultants. Having gained a first class honours degree in building technology from \\ UMIST, she worked as a building control officer with Leeds City Council, and set up her \\ consultancy business in 1988.
}

\begin{abstract}
This paper is based on a presentation given to the Royal Institution of Chartered Surveyors Weekend Briefing for Building Surveyors on the subject of the Disability Discrimination Act and historic buildings. Historic buildings can pose challenges when services need to be provided in a building with public access, and these need intelligent solutions. The case study provides helpful examples of solutions for practitioners in the field.
\end{abstract}

\section{Keywords:}

historic buildings, listed buildings, Disability Discrimination Act (DDA), service providers, UK, access audit

\section{INTRODUCTION}

This paper is based on a presentation given to the Royal Institution of Chartered Surveyors Weekend Briefing for Building Surveyors on the subject of the Disability Discrimination Act 1995 (DDA) and historic buildings. It is not a research paper but a review of current understanding of the impact for historic buildings. There is a level of concern that providing access to historic buildings is unreasonable because the features which people wish to retain are often the ones which would be destroyed by providing access. This opinion remains despite the fact that 95 per cent of people who have a disability do not use a wheelchair, and despite the evidence of access being provided in many historical buildings.

\section{DISABILITY DISCRIMINATION ACT 1995}

The DDA has often been presented as being radical because it requires changes to existing buildings, which even fire safety legislation has not

School of the Built Environment Leeds Metropolitan University Leeds LS2 8BU, UK Tel: + 44 (o)113283 1990 Fax: + 44 (o)113 2833190 E-mail: m.b.smith@leedsmet.ac.uk normally required, provided there have been no other material changes. But does it actually require alterations to buildings by law? The answer is that it could do, as a last resort, where an obstacle is so severe that there is no other way around it, access past or through the obstacle is absolutely necessary for all concerned, and it would be reasonable in all the 
The focus of the Act is on results, not method

\section{The service must comply - not the building}

circumstances to make that alteration, but this would be a very unusual situation.

Part 3 of the DDA is a piece of legislation designed to avoid people who are disabled being discriminated against because of their disability when trying to access certain services. Discrimination is likely to occur because of an obstacle, which may be a physical obstacle (structural or otherwise), an attitudinal obstacle, a procedural obstacle, or even an obstacle created by omission. If someone could be discriminated against when trying to use a service, there are four recourses. The obstacle can be removed, or altered so that it no longer has that effect. A reasonable means of avoiding it can be provided, or a reasonable alternative method of making the service in question available to disabled persons could be offered. There is no order of preference, it all depends on the specific circumstances. Any one of the four methods may be more appropriate, reasonable and cost-effective than the other three. Provided that the discrimination no longer is experienced, the solution is effective. To use the words of Vivien King (2005), Barrister, the focus of the Act is on results.

\section{THE BUILDING AND COMPLIANCE}

It is the service provider who must comply with the DDA, not the building occupied. If a seller wants to sell a car, they could invite buyers to see it inside a showroom, outside on the forecourt, or drive it around to someone's house. They could advertise it in a magazine, newspaper, flyer or on the screen, and invite buyers over the telephone, by internet or post, then get it delivered to a buyer, unseen before purchase. If the seller's office is not accessible to wheelchair users or other people with mobility problems, there are many other ways of enabling someone to buy the car. The service offered here is car purchase. That is the service which should not be discriminatory if a purchaser has a disability.

There are many services which do not need a particular building to be accessed. When carrying out access audits, the professional should be looking to see if the service can be offered in a different way if a physical obstacle is present. A challenge to building professionals is not to advise building works when an alternative solution would be equally acceptable.

On the other hand, there are many examples where the building does form part of the service. For example, a person may wish to worship alongside fellow worshippers in a religious building, they may wish to look at medieval features in a specific listed building open to the public, or they may wish to have coffee with friends in a particularly pleasant restaurant in the middle of an ancient city. To divorce the service from the building may not be appropriate or give an equivalent experience. Access into the building and to the facilities offered in that building, for as many people as possible, then becomes a priority.

\section{HISTORIC BUILDINGS}

There are a number of different levels and types of historic building and the term is used for a variety of meanings. For this discussion, the term is used generally. Buildings acquire a number of challenges when put to use in a different historical period. A building's given use could be very 


\section{Historic buildings are survivors}

\section{Do not introduce architectural disability}

different to the one it was originally designed and built for. It could have been built in an era of different priorities. It may be listed, and some of the features which resulted in the listing may be those features which make access difficult for some people. It may be aesthetically important, which may make some obvious adaptations for access unacceptable. It could be constructed from expensive materials making any alterations much more expensive than for other buildings. It could contain a combination of these issues or all of them.

One advantage of historic buildings is that they are survivors. There are few survivors, either built or organic, which have not managed that survival without adaptation, resourcefulness and change. Such is the nature of survival. Equally, the changed building has to be successful in its new adapted form. In evolution, a mutation that works goes on to better things, one that does not work does not survive.

The challenge to building professionals looking at a building which has obstacles to access is therefore to find good solutions not involving alterations. Only if that recourse is not possible or reasonable should a construction solution be found. Presenting the case that because a building is listed or historic it cannot be altered is not acceptable. Listed and historic buildings are only still here because they have adapted to new eras in a way that works. There are few reasons why they cannot adapt again without losing their historic integrity.

Building professionals may need to convince their clients that reasonable access should be provided, in a way that shows business sense as well as compliance with any legislation. The Disability Rights Commission (DRC) has estimated that there are ten million disabled people in the UK, which equates to a lot of potential customers (Disability Rights Commission, 2006). In addition, there are many others who are not disabled but who would also benefit from improved physical access, for example, elderly people, parents with babies or small children, customers with a broken leg from a skiing accident, a client just in from the USA still with his luggage. The DRC states that one in four potential customers is either disabled or has a close friend or relative who is, and this equates to annual purchasing power of $£ 40-50 \mathrm{bn}$. Providing access need not be regarded as a charitable action.

It is not just historic buildings which pose problems for people, even new buildings can be problematic. It is also not just historic buildings which meet challenges when alterations are proposed. Professionals are coming to understand that their viewpoint needs changing. The focus should not be on a few problem people who want adaptations made to enable their access to buildings; rather buildings should not be designed in a way that a quarter of the population is inconvenienced to an unreasonable extent just because something they need is inside such a building.

'Architectural disability' is a term explained by Julienne Hanson, Professor of House Form and Culture, University College, London, and used to describe a situation which occurs when the physical design, layout and construction of buildings and places confronts people with hazards and barriers that make the built environment inconvenient, uncomfortable 
or unsafe for everyone to use and may even prevent some people from using it at all (Hanson, 2004). The built environment can disable people by poor design which is often present in details. Steps which are comfortable to use can be disabled by a handrail design which is not easy to grip if manual dexterity is an issue. Similarly, if signs are absent or unclear or the surface material is slippery, this can result in steps being a hazard. Ramps which are too steep or too long cannot be used comfortably by many people with limited balance or ankle manoeuvrability problems. An accessible WC, which is used as a storeroom because inadequate storage facilities were provided, is not going to be accessible to the people it was designed for.

For a building and its environs which present an architectural disability, the professional needs to find a building solution that works, usually in terms of performance requirements, aesthetic requirements, cost requirements and a balance between conflicting interests. This is no different to the normal day-to-day work of many building professionals.

\section{LEGISLATIVE MATTERS}

As always, there is the need to consider compliance with legislation, for example, Building Regulations, fire legislation and planning laws. Legislation usually takes account of special circumstances. For example, in the Building Regulations' Approved Document Part M (ADM) it states that 'the aim should be to improve accessibility where and to the extent to which it is practically possible, always provided that the work does not prejudice the character of the historic building' (The Building Regulations, 2000). Therefore, if a certain solution might prejudice the character of the building, the professional would endeavour to find a different solution that does not do this. In the same way, if a solution conflicts with fire regulations, it would not be a good solution.

Looking first at Building Regulations, if material alterations are being carried out to an existing building, compliance with Part $\mathrm{M}$ is a likely requirement. ADM gives a host of useful advice on how to comply with Part M; however, with historic buildings some of this advice may prejudice the character or features of the building. An access statement should be submitted with the building regulation application. This statement can be very useful in presenting the situation and specific circumstances of an historic building to the authorities in a way that plans cannot. In the access statement, the applicant can state the limitations and issues of the particular building and project. It can present the concerns of planning authorities and English Heritage where applicable. It can also state when and where different advice to that given in ADM is being used and why, showing how accessibility is being provided in other ways.

There has been some confusion regarding buildings being constructed in compliance with Part M becoming occupied and then falling foul of a discrimination risk or claim under the DDA. Buildings themselves (not 


\section{Ugly access solutions are not good solutions}

the service) have therefore been given a ten-year reprieve. This ten-year rule covers the following circumstances:

- The building is built in compliance with Part M.

- A particular part of the building complies with Part M and the recommendations in ADM.

- That part of the building causes an obstruction which results in discrimination of a disabled person under the DDA.

By virtue of the ten-year rule, the occupiers cannot then be required to alter that part of the building under the DDA; however, the service does not get a reprieve and the service itself is likely to have to be altered so that it is not discriminatory.

There has been confusion with people thinking that a building in compliance with Part $\mathrm{M}$ is therefore in compliance with the DDA for ten years. That cannot be the case because the building cannot comply as it is the service which must not be discriminatory, not the building. For example, a handrail that has been provided in accordance with Part M which later is found to cause an obstruction to the public because of the way the service is provided, does not need to be changed for ten years, but the service will need to be altered so that it is not discriminatory.

One cannot use the idea that if a building has been built in conformance with Part $\mathrm{M}$ it is somehow exempt from the requirements of the DDA. Part M is concerned with building works, and the DDA is concerned with discrimination in the service offered.

Planning issues are different to Building Regulations, and are not concerned with construction but rather the aesthetics, and practical and safe working of the built environment. The DDA does not take precedence over planning laws and there is no reason for it to do so. Access solutions which are ugly or not in harmony with the surrounding environs are not good solutions. Planning matters therefore have to be considered for any design solutions for historic properties. Conservation is often a main priority when dealing with historic buildings. But there are many definitions of conservation, for example:

- 'Making a building fit for some socially useful purpose' (International Council of Monuments and Historic Buildings, 1964).

- 'Action taken to prevent decay. Embraces all acts that prolong the life of our national and cultural heritage' (Fielden, 1994).

To make a building useful in society is an essential part of conservation because the desires for retaining it and spending money on it are all the greater. But there can be conflicts between access proposals for the DDA and planning considerations. The value of a particular item sought to be removed for the DDA may be so great that it ought to remain unaltered for posterity (Mynors and Booth, 2005). Removing it would not be a good solution in that case. In fact, under the DDA the removal or alteration would in itself be unreasonable when seen in the wider context of the national heritage. Removal or alteration are only two of the four 
History versus DDA

\section{The role of local authorities}

choices given by the DDA for dealing with physical obstructions. The professional in this case should look for a different solution, for example, one that provides a reasonable means of avoiding the obstacle or one that provides a reasonable alternative method of making available the service in question.

So can the fact that a building is of historic importance provide a reason for not having full access? The answer to this question is that it depends on the circumstances. The simple reason of historic importance is not acceptable on its own. There is no duty to carry out works for the DDA before planning consent has been obtained. Planning consent should be gained first. The presumption for a particular item's retention may outweigh any argument for change based on the DDA.

If the service is particularly obstructed by an element that cannot be changed reasonably without destroying the property's important historic value then the client has some options. First, they should apply for consent to remove or alter the item. There is some protection in the waiting period while consent is being determined, although this is just for the way in which that item is obstructing the service - there are likely to be many ways in which access to the service can be improved which do not depend on the item in question. If, as expected, consent is declined, then the service provider can fulfil their duty under section 21 of the DDA, to take such steps as are reasonable, by pursuing the petition to court. The court would then take all circumstances into consideration to reach a decision. Should the decision be that the historic feature is not to be altered then the service provider is on safe grounds for not altering the feature but may still have to find an alternative way of providing the service. The assumption that a building is historic and therefore cannot comply with the DDA is not a valid one. It is the service that must not be discriminatory, not the building.

There is no statutory or other duty on planning authorities to have special regard for disability issues. This does not assume that they do not, in the same way that authorities consider fire safety and other health and safety issues. Authorities also work to guidance, for example, Planning Policy Guidance (PPG) 15, paragraph 3.28 (1994) states:

'It is important in principle that disabled people should have dignified easy access to and within historic buildings. If it is treated as part of an integrated review of access requirements for all visitors or users, and a flexible and pragmatic approach is taken, it should normally be possible to plan suitable access for disabled people without compromising a building's special interest. Alternative routes or re-organizing the use of spaces may achieve the desired result without the need for damaging alterations.'

Currently (in the last quarter of 2005), there are concerns that local authorities are giving less weight than they could be to pressing for issues over access to historic properties to be resolved. Issues regarding access and historic features can conflict but there is usually more than one solution and the solution with the least adverse effect should be chosen.

For properties listed as grade 1 or $2^{*}$, the permission of English Heritage also has to be obtained for removal or alteration of historic 
Historic properties may have many helpful features features. English Heritage considers itself to be the lead advisory body on providing access to historic buildings in England and states that access should be celebrated with high-quality designs, sensitive to the special interest of historic buildings. English Heritage therefore is presenting itself as sympathetic to good solutions for alterations to historic buildings where these are reasonable. Examples of this can be seen in cathedrals and castles throughout England where a grade 1 listing has not stopped the provision of a ramp or accessible WC making the premises easier to access for many people, without adversely affecting their character.

Recent case law has determined the considerations required to be taken into account by a planning authority where proposed works of alteration involve the demolition and therefore destruction of part of an historic property. In this context, 'alteration' includes demolition of a part of a building, 'demolition' means pulling down the whole building, and 'significant' (ie demolition of a significant part of a listed building) should be understood in terms of qualitative aspects not proportion. Refer to Shimizu (UK) Ltd vs Westminster City Council 1997 and $R$ (on the application of Sullivan) vs Warwick District Council and others 2003 for further details.

\section{CASE STUDY}

It is the service not the building which must not be discriminatory. Despite that, the biggest challenge to resolve is usually where the public must enter the building to access the service. The following case study presents an example showing the types of difficulty encountered. It concerns a three-storey, grade 1 listed, Georgian house, now used as a museum of Georgian life, owned by a charitable trust which wanted inclusive access but had limited monetary resources. The trust set out an access strategy and carried out an access audit.

The access audit was very useful to the clients. It concluded, after taking advice from the DRC, that the client had to consider its service to the public with a duty under DDA Part 3 to the public, but not to staff, volunteers or trustees. (Case law may clarify this and there would be duties to employees under Part 2.)

There were many features of the current service which aligned with guidance, for example, internal horizontal circulation, the willingness of staff to help and suitable contrasts in decoration to distinguish between walls, doorways and floors. The audit report presented the case that there was probably no duty to alter the toilets, because although there was not a fully accessible WC, there were no public WCs, therefore there was no discrimination of a particular portion of the public.

The audit raised recognition of obstacles which might cause discrimination and which were relatively easy to rectify without a large monetary outlay, for example, the displays in the shop, lack of a written tour, advertising material and public seating. These needed management and staff input and minor changes once the problems were understood. Building professionals may not have considered these issues as they were not related to building works; however, access audits should include 
these points because the DDA is about the service not the building, and clients expect their consultants to give appropriate advice.

A number of issues were also raised as being obstacles which had the potential to result in discrimination but which were not so readily rectifiable. For example, access into the building, vertical circulation and a special display.

The special display was an award-winning display of 18th century household equipment. The display was fascinating for those who could see and read it. Unfortunately, there were drawbacks for people of small stature and for those with visual problems who either could not focus on the small text or were affected by too much contrast caused by spotlights shining onto reflective glass in an otherwise darkened exhibition. It was a travelling exhibition and, in this case and situation, there were no recommendations that it be re-done, but the audit report suggested that for the next exhibition disability issues should be explored.

The architectural disability of access steps at the front and rear was the major consideration, causing problems of access for people with mobility problems, including arthritis, and wheelchair users. The building was situated straight off the public pavement at the front, and because of the total rise of the steps any ramped solutions would involve very long ramps to the front or rear which would impinge excessively on public pavements. The existing handrails were also poorly designed for people with manual dexterity problems or skin sensitivity to cold, and the handrail to the front steps was not appropriately designed for people to use to help them ascend or descend the steps.

While access designs for entering the building were considered, other access issues were dealt with. These could be described as benefiting the other 95 per cent of people with a disability, because they covered aspects which were not connected with wheelchair use. They included:

- Access policy

- Advertising literature

- Loop system

- Visitors' chairs

- Written (large print) tour

- Clear circulation routes

- Helpful staff/personal guides

- Removal of trip hazards

- Touchy-feely days

- Spotlight directions

- Decorations/flooring

- Internal handrails

- Internal doors

- Procedures for assisting dogs

- Toilets (staff).

Some of these issues were good and a point was made of these for the clients, so that if any changes were proposed in the future, the clients would know what to look out for. Aspects of some of the above could have 


\section{Non-structural suggestions welcomed by clients}

been better and suggestions were made. Some items needed improvement. Varieties of solutions were suggested which the clients stated were manageable, helpful, welcomed and cost relatively little. Where more than one solution can be presented for a particular issue, the client has the opportunity to determine which would be best for their circumstances and business. Solutions also can be helpful in other areas, for example, in the case study a written tour was produced for people with hearing difficulties, which was consequently translated into French and German for foreign visitors.

The issue of toilets was raised above. As stated, the existing toilets were only for staff use. Toilets are always seen as a major challenge and high-cost area. In this property, because time had been taken and advice from the DRC had been used to decide who the public under consideration were, it was determined that the toilets, although not fully accessible, were not resulting in discrimination to the public using the service of the museum. This was accepted very much on current advice - there may be future test cases in the courts which reverse this understanding - and at the time of the access audit the clients were happy to be meeting their obligations in this respect.

Because of the helpfulness of staff, the clients were very keen to accept that a person with a 'can't wait' card (who may have Crohn's disease, colitis or a continence disorder) should be permitted to use the staff toilets with an accompanying member of staff for security. Training regarding Crohn's disease, colitis and the use of 'can't wait' cards was requested. This was just one of the situations where the clients were prepared to go beyond their statutory duties. It was helpful for them to know where their duties stopped and generosity started.

Furthermore, it was decided that, when funds became available, an upgrade of the facilities to improve them for all staff was desirable. The accommodation was not such that current staff had major problems of access, but many of the volunteers were elderly with typical age-related issues. Improvements envisaged included upgrading to WCs accessible to ambulant disabled people, with sufficient space, support rails, better decoration and contrast, better placed mirrors and towel dispensers, chairs in the waiting area and shelves.

\section{Wheelchair users}

The remaining 5 per cent of disabled customers, including those who use a wheelchair and people with severe mobility problems, was also considered. A number of radical solutions were considered and presented to the planning authorities and English Heritage at an early stage for discussion. These discussions proved very helpful for all parties, as proposals were suggested and amended or discarded with full discussion being taken on the benefits or drawbacks of each. Eventually, Listed Building and English Heritage permissions were gained to convert a front ground floor window to a door which opened onto a platform lift giving rise to the entrance floor, and to replace an internal 1970s spiral staircase with a small evacuation lift giving rise to the first and second floors. 


\section{Test of} reasonableness
Management measures were included for evacuation procedures. These were not cheap solutions, but there were no cheap solutions in this case.

The test of reasonableness for access includes one of resources available to the service provider. If the charity could prove that the costs of these improvements were beyond their means, this would have been a major defence in any discrimination case taken to court, as would the facts of access having been improved for some 95 per cent of disabled people. Any remaining problems with access for people could be highlighted on advertising literature and web pages, to prepare potential customers for the situation should they decide to visit.

\section{SUMMARY}

In summary, good design is rarely easily come by for any building proposals. An iterative process is required to test solutions with all relevant parties. There are particular issues to be considered for a service offered from historic premises to which the public needs access. Building professionals need to find good workable designs for level access, to find appropriate solutions for the 'other' 95 per cent of people with a disability, and to ensure high-quality, detailed access designs which are sensitive to the special needs of historic buildings.

\section{References}

The Building Regulations (2000) Approved Document M - Access to and Use of Buildings, 2004 edn, The Stationery Office, London, UK.

The Disability Discrimination Act (DDA) (1995) (c. 50) The Stationery Office, London, UK.

Disability Rights Commission (2006) Services and Transport, available from www.drc.org.uk/ services, accessed 20 April.

Fielden, B (1994) Conservation of Historic Buildings, 2nd edn, Butterworth Heinemann, London, UK, p. 3 .

Hanson, J. (2004) 'Defining domesticity: Housing and care choices for older people', lecture given at Leeds Metropolitan University, Leeds, UK, 4 November.

International Council of Monuments and Historic Buildings (1964) Venice Charter for the Conservation and Restoration of Monuments and Sites. Article 5, ICOMOS, Venice, Italy.

King, V. (2005) Personal interview, RICS DDA meeting, London, 16 March.

Mynors, C. and Booth, A. (2005) 'Access for disabled people to historic buildings', Context, Edition 84, May.

ODPM (1994) Planning Policy Guidance 15: Planning and the Historic Environment, The Stationery Office, London, UK.

$R$ (on the application of Sullivan) $v$ Warwick District Council [2003] EWHC 6068 April 2003 (Administrative Court).

Shimizu (UK) Ltd v Westminster City Council [1997] 1 All ER 481; [1997] UKHL 3; [1997] 1 WLR 168. 